\title{
PAUL FEJOS, 1897-1963
}

\section{Ralph SolEcki}

$\mathrm{P}$ AUL FEJOS, President and Director of the Wenner-Gren Foundation for Anthropological Research, died of a coronary attack on April 23, 1963. After four operations, his staunch heart could stand no more.

He was one of the vanishing breed of anthropologists who came into the field from other disciplines, and he was a man of many facets. The American Anthropological Association gave him a Special Award just five months before he died "... for his manifold efforts in the service of the profession and for his own distinguished career." Few who knew this shy and very modest man would suspect that he was a famous film director. Fejos' bitter disappointment at not being able to direct All Quiet on the Western Front, which he had induced Universal to buy, caused him to sever his Hollywood connections and ultimately to give up pictures. Such was the historical accident which led to anthropology's gain.

Fejos was administrator, scholar, lecturer, teacher, scientist, and leader among men, and undoubtedly the wisest choice Wenner-Gren could have made to direct his foundation. A summary of Fejos' personal and professional history, honors and decorations, memberships in professional scientific societies, chief fields of research, and publications are listed in the "Eulogy for Paul Fejos" by John W. Dodds, in Current Anthropology, Vol. 4, No. 4, 1963. It is not repeated here.

Paul Fejos was born in Budapest, Hungary. He was a Hussar cavalry officer but changed mounts to the airplane in the First World War. After wartime service, he attended the Royal Hungarian Medical University, where he received his degree in medicine. The years 1923 to 1926 were spent at the Rockefeller Institute for Medical Research in New York. He left this for motion pictures in Hollywood, following an earlier interest in Budapest. After his quarrel with Universal, he returned to Europe and eventually began to make ethnological films. He became associated with Wenner-Gren, whom he met in southeast Asia on one of his ethno logical film-making trips for a Scandinavian expedition. Fejos saved Wenner-Gren from a charging tiger on a hunting trip, bonding their friendship. In 1941, the Viking Fund (in 1951 changed to the Wenner-Gren Foundation) was established by Wenner-Gren. Paul Fejos was called to assume directorship of the Foundation later the same year. Both men believed in crossdiscipline research, new areas of investigation, and the value of world-wide unity and co-operation among anthropologists. Supper and roundtable conferences, international symposia at Burg Wartenstein, the Viking Fund medal awards, the Viking Fund publications, fellowships and grants-in-aid, travel grants, visual aids, and the casting program are all part of the daily business of this unique foundation, unprecedented and today unmatched by any other organization in the world. On the large wall map behind Fejos' desk in his New York office are multicolored pins, reminders of the various points that the Wenner-Gren Foundation has touched over the globe.

Probably the most important role of Paul Fejos as director of the Foundation was that of a stimulant and catalyst. The Foundation has been the sympathetic source of help, especially in the lean years after the war, to which the individual researcher could turn for grants-in-aid. Without it, plans may not have been forged in the first place, and much of the progress in ar-

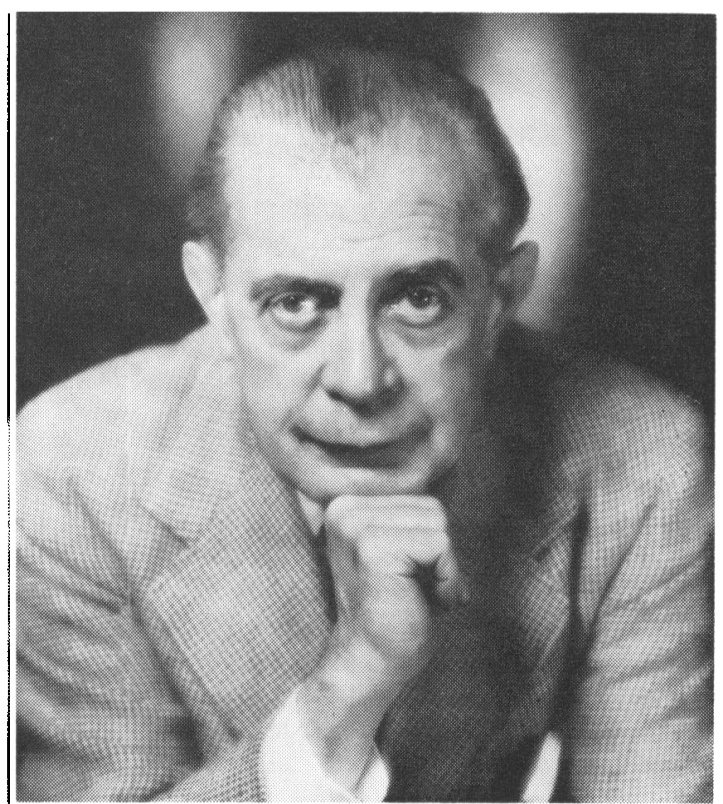

Paul Fejos 
chaeology achieved today would have still been daydreams in the minds of many of us. Paul Fejos was interested in the small institution as well as the large. The late John Goggin of the University of Florida expressed surprise that Fejos had troubled himself to come and see him to talk about Goggin's program needs. With the same precise calculation and sure judgment instilled in him from his wartime flying, boxing, and saber-fencing days, Fejos shaped the decisions on "risk" projects, which not infrequently led to real contributions.

When we review the numbers of grants-in-aid awarded by the Wenner-Gren Foundation, we have the impression that archaeology and physical anthropology were favored by the Foundation. For the year ending January, 1962, archaeology was awarded the greater share of 97 grants, or $42 \%$ of the total. However, we should remember that the other subdisciplines of anthropology had access to many more foundations. Emil Haury, one of the first archaeological grantees under Fejos' administration, observed in the 20th Annual Report of the Foundation that about $30 \%$ of the aid received between 1941-61 was allocated to archaeology; this amounted to about $\$ 700,000$ for archaeology and related studies.

Paul Fejos, an accomplished technician himself, was much interested in the applications of scientific techniques to archaeology. These included chemical analysis, spectroscopy, pedology, geophysical studies and, naturally, photography in all of its aspects. His vision supported the radiocarbon dating technique, especially during the period of its early development in the late 1940's. At the time of his death, he was instrumental in the perfection of a new casting technique involving the use of plastics to do away with the unsatisfactory plaster-cast modeling of anthropological specimens.

With the death of Paul Fejos, which followed by just two years the death of Axel WennerGren (1881-1961), an era in anthropology is passing. We in archaeology feel that we can claim him as our own. Paul, as he insisted on being called, without doubt knew more anthropologists personally than anyone.

COLUMBIA UnIVERSITY New York, New York December, 1963 